\title{
ARE We EfFECTIVEly Teaching Today's COLLEGE STUDENT?
}

\author{
Candice Dowd Barnes, Ed.D, Patty Kohler-Evans, Ed.D, and \\ Rachel A. Wingfield, M.S. \\ Department of Elementary, Literacy, and Special Education, University of Central \\ Arkansas, Conway, Arkansas, USA.
}

\begin{abstract}
Evidence suggests that twenty first century college students have less aptitude and less interest in academic learning than their predecessors. This poses a challenge to faculty who are charged with passing knowledge to the next generation of teachers, scientists, managers and others whose field necessitates a degree from a college or university. The authors examine this assertion by taking a closer look at how faculty provide intellectual stimuli to their students, how technology helps or hinders learning, and the complex relationship between faculty and students. Three broad themes are explored: helping students understand the higher education experience, keeping students engaged in and out of class, and continuously assessing for improvement in students' relationships with those charged with educating them. Specific recommendations, grounded in research, are made for each area explored. The authors conclude that making changes in how faculty approach the experiences students have, will significantly improve the quality of those experiences.
\end{abstract}

\section{KEYWORDS}

Teaching Effectiveness, College Students, Faculty Development, Faculty-student Relationships

\section{INTRODUCTION}

In a recent book, Bok suggests that college students in the twenty-first century have less aptitude and less interest in academic learning than previous generations of college students (Bok, 2013). Brouse et al., (2010) found higher levels of intrinsic and extrinsic academic motivation in firstyear students than senior level students. This alarming finding can serve as a driving force for faculty to capture and cultivate the motivation in first-year students to sustain this interest in learning throughout their four-years of learning. Bok's conclusions and the findings of Brouse et al., (2010) provoke some examination of the processes by which college faculty pass on knowledge to students. What does this say about the intellectual stimulus faculty members are providing in their classrooms or the value students place on their education and learning? What does this say about students themselves? What part does technology play in the instructional process? Finally, what does this say about the relationship between faculty and students; how well are the two groups connected?

Since 1961, there has been a forty-year decline in the number of hours students spend on course preparation and studying. These data are an alarming trend. A study conducted by the University of California, as cited in (Bok, 2013), reports that students spend an average of thirteen hours a week on their studies and forty-three hours a week engaged in other activities such as television, social networking and socializing with friends. This disproportionate number of hours spent 
studying versus socializing begs faculty to consider the methods in which they are providing instruction and if it is the most engaging technique for the 21 -st century college student.

In this article, the authors present a case for improving the way college faculty engage their students. Three broad themes are explored: helping students understand the higher education experience, keeping students engaged in and out of class, and continuously assessing students' relationships with those who seek to educate them. In addition, the authors provide several research-based recommendations in each area.

\section{BUILding a CASE}

Recently, while attending a leadership conference, an attendee shared his frustration with the lack of preparation students have for class and learning. He jokingly said, "I tell my students not to let a little thing like college and learning get in the way of their social lives." The audience laughed, but for some students, this is a real and present commentary. At times, it appears that students are engrossed in maintaining the integrity of their social lives, oftentimes sacrificing their learning. Students' lack of preparation may be tied to fear of participating in class. Instead, many students fall behind in their studies or, worse, are absent altogether (Bledsoe \& Baskin, 2014). It also seems that faculty members have a tough time engaging and exciting students in ways that incorporate new innovative ideas and methods.

The purpose of this article is to begin an exploration of how faculty members might impact students' educational experiences in ways that increase the likelihood that those students, especially freshmen and sophomores, take more ownership of their learning. The authors begin to examine how faculty members can help students understand the significance of the higher education experience related to their professional and personal lives. The authors begin to explore the relationship between faculty members' own inadequacies in the delivery of instruction and the use of effective teaching strategies, including technology, designed to meet the needs of all students. Finally, the authors also wish to delve into faculty perceptions and attitudes about assessment issues. Commentary on faculty members' assessment of students as well as how they assess faculty through end of course evaluations provide some texture to the discussion. Inherent in this examination is the implication that faculty need to move beyond lecture and the way learning is typically evaluated to enhance the quality of instruction, focus on student relationships, and engage in meaningful self-evaluation.

In earnest, these areas of exploration will require a much more thorough investigation than is offered in this brief article. Nevertheless, the authors offer a few considerations that might serve as conversation starters for faculty members concerned about how and what students are learning, how students are applying their learning, how they are transferring knowledge into their professional practices and personal lives, and how faculty behavior and their perception impacts all of these issues. In the following sections of this article, the authors suggest a few recommendations, reminders, and routines to move thinking forward.

\section{RECOMMENDATIONS FOR FACULTY}

In this section, three broad areas will be explored. In the first, suggestions are made for faculty to assist students to more fully understand the college and university experience. Next, faculty members are offered a few ideas for keeping all students engaged throughout their classroom experiences. These suggestions will be followed by ideas for self-assessment as well as student assessment. This section ends with a challenge to keep all course curriculum relevant and reflective of the highest content standards. 
International Journal of Education (IJE) Vol.8, No.4, December 2020

\subsection{Recommendations to Help Students Understand the Higher Education Experience}

\subsubsection{Be Student-Centered.}

As reported in Best Colleges (2020), fewer than 10\% of foster kids graduate from college, $14 \%$ of community college students are homeless, $30 \%$ of incoming freshmen are the first in their families to go to college, and $26 \%$ of undergraduates are raising dependent children. In a 2020 article, the U.S. News reported that one in three students might not return for their sophomore year. These alarming statistics help illustrate the importance of making sure that institutions of higher education completely focus on students, and that may mean developing an understanding of who students are as well as engaging them in class through instruction and discussions.

To fully connect with students, faculty need to recognize and value the importance of providing personal attention to individual students. In a comprehensive report utilized by the Gardner Institute on student success (Hearn, 2006), identified specific success factors which include frequent contact with faculty, development of connections between classroom work and learning opportunities outside the classroom, assessment and frequent feedback, and respect for diversity among students. Frisby and Myers (2008) reported that when students perceived faculty as building a relationship and rapport with students, students reported participating in class and an increase in their affective learning, motivation, and satisfaction. Building relationships and establishing rapport with students is the first step towards being student-centered and giving personal attention to students, rather than knowing students by the row they sit in during class.

For decades, students in the university setting have been expected to sink or swim, and faculty have prided themselves on being able to weed out those students who did not quite measure up or make the grade. Some students face significantly challenging paths. In a study by Jorgenson et al. (2018), the researchers found that students saw their instructors as more than educational providers; they were figures with whom personal relationships could be forged. Students' descriptions of connections with instructors did not reflect classroom teaching style or pedagogical competence, but rather the degree to which students perceived the instructor cared about them as people. Brown and Starrett (2017) surveyed students about their higher education experiences and found students worked harder and enjoyed the educational process more when they felt connected to a class. They also reported that connectedness helped them better internalize and understand course material. Students indicated that the more connected they felt, the more comfortable they were in class, which in turn led to increased participation in-class activities (2017).

\subsubsection{Implementing Technology}

For some, technology can be a barrier to engage in a more student-centered approach to learning. However, exploring ways in which one might use technology to increase meaningful interactions, rapport, and relationships can prove helpful in building a personalized learning environment. Brannon (2005) surveyed college students to understand their perceptions of their interactions in different course formats (i.e., face-to-face, hybrid, and completely online environments). Overall, students rated their interactions with instructors as good. However, when analyzing interactions with faculty concerning the delivery type, students perceived online and hybrid as good and faceto-face as average to good (Brannon, 2005). Most students in colleges today are armed with tablets, smartphones, and other devices that have been in their possession for years. Relating with students can be tough, especially given the technological climate and the number of hours students spend on social media. The results of Brannon (2005) highlight that technology 
integration can increase and develop positive interactions between students and course instructors.

Before using various modes of technology to interact and connect with students, it is crucial to understand how faculty feel towards integrating technology. Marzilli et al. (2014), surveyed faculty members to understand technology integration in their respective classrooms. Overall, the faculty held a positive stance toward technology use in the classroom. However, when asked to identify the opportunities technology provides, no responses reflected using technology as a bridge to connect with students. Although faculty utilized and felt positive about integrating technology, the instructors were not utilizing it to its full potential. Technology integration may lead to not only confusion on the part of the faculty member, but for the students as well.

\subsubsection{Expect and Respect Moments of Confusion}

Confusion and learning are both integral parts of the learning process since this promotes students' ability to master the content. However, respecting student confusion is entirely different. Respecting their confusion requires unwavering patience and consideration of their prior knowledge - what skill sets and knowledge do they possess for thinking, and how do they apply what they are thinking? Admittedly, there are times when students' confusion, coupled with a lack of coping mechanisms, can make for a long semester.

Likewise, students should expect to prove and demonstrate content mastery. They should be expected to evaluate their own learning and identify where they need to improve and where they are excelling. Too many college students are paralyzed by the fear of failure (Bledsoe \& Baskin, 2014), so much so, that they retreat from thinking altogether and bail out on the learning process. According to Costa (2001), engaging in five thinking themes can impact how one engages students and delivers instruction. He suggests that one needs to learn to think, think to learn, think with others, and think big, and think about the thinking. Collectively, these five thinking themes are included in a more extensive set of specific behaviors collectively referred to as habits of mind. While other researchers have expressed some of these thinking themes, these themes, when combined, connect the vast complexity of thinking to ones' higher cognitive and metacognitive behaviors. Utilizing greater cognitive and metacognitive behaviors allows for more reflection, relevance, and responsiveness.

Equally important, students should be expected to transfer that knowledge into other courses and other aspects of their lives. Faculty members should create moments of cognitive dissonance for students to challenge and optimize their thinking, and then, find ways to help them resolve those moments of confusion. Some of the most important lessons in life are learned from experiencing moments of disequilibrium, especially with the support of one who can help navigate through the rough waters. As faculty, our job calls us to encourage, challenge, and provide multiple opportunities for growth, knowing that growth requires a bit of discomfort at times.

\subsection{Recommendations to Help Faculty Meet the Needs of All Students}

\subsubsection{Use Authentic Experiences}

Faculty members should resist the temptation to decrease the amount of rigor and difficulty of course assignments simply because students complain about the difficulty of coursework. Instead, faculty members might consider authentic strategies such as service-learning, reflections, projectbased learning, and use of case studies that will help students make the connection between the content and real-world contexts. Students' learning deepens when afforded opportunities to apply 
that knowledge in clinical experiences and through internships, when available and appropriate. Student thinking should be tested and challenged. Faculty members should not shy away from those activities that challenge students' current scheme. However, they should cautiously use those activities to guide students' learning - learning that may or may not always be graded or rewarded.

College students should expect to engage in authentic activities both inside and outside of the classroom that encourage solution-focused learning, collaboration, deep thinking, and active engagement. Solution-focused learning or thinking encourages students to focus on what is working well in their lives and learning and increase the habit of engaging in it (Solution Focused Thinking | NBSS, n.d.). Collaboration or collaborative learning activities vary, but focus on students' exploring and applying the course material and not the faculty member merely explaining it (Smith \& MacGregor, 1992). The concept of deep thinking has traditionally applied to the middle or high school classroom. However, the strategies to encourage deeper thinking in students is applicable in the college classrooms of the 21st century. Martinez (2020) highlights six strategies to encourage deeper thinking: connect, empower, contextualize, reach, inspire, wire via technology usage. Faculty members can take these six strategies and incorporate their use to encourage students to think deeper about the course material and promote active engagement in applying the course material. Incorporating deeper thinking and authentic activities promotes student engagement and learning in the classroom.

\subsubsection{Be Engaging}

For decades, faculty have relied on imparting knowledge through the traditional lecture without inviting students to activate their metacognition. Studies have reported that lecturing is one of the least effective ways to teach students. Although it is appealing to professors because it allows one to cover a great deal of information, research has shown that students remember less than half of the information and only a quarter of the information a week later (Bok, 2013). Similarly, Moore (2005) showed only $10 \%$ retention after three days of listening to lecture (as cited in Roettger, Roettger \& Walugembe, 2007). Other studies have found that when students are trying to write down the information, it is often inaccurate. Listening is undoubtedly a useful skill to develop. However, it does not guarantee that students will retain enough information to demonstrate content mastery or apply what they have learned in a meaningful context.

Creating a student-centered environment means that each student is viewed as a unique individual with very specific learning needs and abilities. While it has been stated that instructors need to focus on the needs of each student, accomplishing this takes more effort than assembling the perfect lecture. Even at the level of higher education, effective differentiation suggests that attention is directed at providing multiple forms of learning opportunities simultaneously in a single classroom. Differentiation addresses differences in student interests, preparation, and strengths through a variety of learning pathways (Mintz, 2016). According to Dosch and Zidon (2014), differentiation in higher education is an effective method for teaching college students. An instructor can differentiate in numerous ways: content (using several sources of information), process (including a variety of learning activities), product (allowing students to demonstrate what they know in different ways), and affect addressing student emotions about school-related issues (Tomlinson, 2001).

Another lens for examining student-centered environments is Universal Design for Learning (UDL). The UDL framework provides guidelines for teachers when they create, instruct, and assess the delivery of content. UDL targets the needs of every learner in the classroom by focusing on three underlying principles: multiple means of representation, action, and expression, 
and engagement. According to Kohler-Evans et al. (2019), faculty members recognized for excellence utilize UDL principles, which include the creation of positive learning environments, the use of humor, active engagement, and explicit structure. By using a UDL framework, all higher education students have access to the curriculum in ways meaningful to each individual.

\subsubsection{Be Thoughtful in Building Course Content.}

Some schools and universities are moving to more competency-based learning and personalized learning. Competency-based learning is defined as a system incorporating different methods of instruction and assessment based on students' learning capacity and skills they are expected to learn throughout their education experience (Great Schools Partnership, 2014). Personalized learning is the application of this approach in that it customizes instruction and educational strategies to address students' individual learning needs, interests, and diverse backgrounds (Great Schools Partnership, 2015). In many ways, these types of approaches are undergirded by Dewey's belief that mastery of one goal is the beginning of the next goal (Dewey, 1915). Therefore, working to individualize course instruction or, at the very least, differentiating the delivery of instruction and assessments can create a richer learning environment for students.

All learning should move toward understanding and building knowledge - knowledge, that in this context, is aligned with course objectives. Students should then demonstrate content mastery or develop "habits of metacognition" (p. 189) - reflecting on how they process and think about how the information learned can be used to solve problems, engage others, and build the capacity for learning (Bok, 2013). Therefore, an honest and authentic review of how the curriculum is developed is an invaluable step for faculty members to take.

Curriculum is not always based on sound standards, principles, or truths. Sometimes we find inadequacies, inequality, or bias threaded throughout the curriculum. The inadequacies of curriculum are not to accuse anyone of malice, but in truth, faculty members have particular expertise, values, beliefs, and that are often reflected in what we emphasize in our classrooms and coursework. The framing of critical course content begins with identifying those essential learnings that all students must know at the semester's end. Attentive faculty members ask themselves as well as their students' thoughtful questions designed to elicit those questions, that when answered after the course, will indicate the degree to which students have learned necessary content. When building course content, these critical questions shape the individual units of study that will be addressed throughout the course. Also, best practice would suggest that faculty members also engage in conversations with their students about how they wish to work as a community of learners. How will they demonstrate mutual respect? How will conflict be handled? Reflection is also the time to identify how progress will be measured and what learning rituals will be used. Rituals include the use of group projects, weekly quizzes, a routine developed by assignments, or how participation will be graded. These elements of course content construction can be found in the Course Organizer Routine (Lenz et al., 1998), a routine developed to assist students in understanding the "big picture" of a course and how units fit within it.

If the goal of the curriculum is to help students think more deeply, then we must evaluate if it (the curriculum) is truly accomplishing that task. It is also necessary to identify or define what is meant by deep thinking. This is going to be critical for both the student and the faculty member. Students need to understand that it is the expectation, and the faculty members need to articulate that deep thinking is a goal or objective of the course and define what that means and how students' are expected to respond. By engaging in active, comprehensive assessment measures, faculty members can offer greater assurance that they are meeting the needs and demands of both 
students and society. If the data collected through assessment deems the information weak or somehow insignificant, it might be worth abandoning a goal, objective, or some information to insert that which is more compatible, beneficial and valuable to the learner.

\subsection{Recommendations to Address Continuous Assessment}

\subsubsection{Evaluate your Teaching Effectiveness}

Just as K-12 teachers develop different methods and instruments to measure their students' performance, so too should teachers of college students. This recommendation is essential. Without overgeneralizing, faculty members in higher education settings often exhibit a certain ego about their teaching, which might make it difficult to assess their own inadequacies. Evaluating one's own teaching effectiveness involves using assessment tools other than students' end of course evaluations. However, students' evaluations do not always reflect the selfevaluations of faculty's own teaching practices. Miron (1988) sampled instructors and their students using a 20 -item instructional practices questionnaire. The results indicated only a median relationship (.28) between instructors' and students' ratings. The medial relationship between students' evaluations and instructor self-evaluations begs the question of how effective are student evaluations in evaluating faculty's teaching effectiveness and quality. It is imperative for faculty to engage in self-evaluation and reflection regarding their teaching practices. While this research appears outdated, it highlights the trends in evaluating teaching effectiveness. Around the period Miron (1988) conducted his research, the literature focused on faculty self-evaluations of teaching effectiveness, which has evolved into students' ratings of teaching effectiveness and has recently transitioned into peer-evaluations of faculty's teaching effectiveness. This trend in research highlights the importance of faculty taking the time to evaluate their teaching practices to ensure they are using the most efficient practices to teach today's college students.

With the trend in the evaluation of teaching effectiveness moving towards peer evaluations, there are times when faculty members need to seek the opinions of others-times when faculty members need to conference and collaborate or conduct studies and evaluate their teaching effectiveness. Learning and understanding that the tried and true strategies are not working can be an unsettling and sobering reality. If students are demonstrating that they have not retained enough information or cannot apply it effectively, faculty members owe it to students, themselves, and the profession and discipline to evaluate what can be done to make improvements. It is this kind of reframing or retooling that will support and encourage students to optimize their learning and faculty members to maximize their teaching and expertise. Assessment, therefore, can and should be used to improve instruction.

\subsubsection{Use Multiple Measures of Assessment with Students}

University-wide course evaluations have their value; however, those assessments should be coupled with other measures - multiple measurements that more clearly and concisely showcases the students' learning and instructional effectiveness. For example, mid-course assessments can help instructors make changes to the course content, review challenging material, and gather a general idea of what students know and how they might apply the information. Additionally, developing more performance-based assessments - authentic assessments are a more accurate indicator of students' knowledge and their application of content. These types of assessments also allow faculty members to offer feedback, which might be far more valuable to the student's learning than merely writing a grade or score on their assignment. 
Roettger et al. (2007) believe faculty are responsible for moving past simply lecturing to students in order to cultivate a "class culture of shared learning" (pg. 129). Therefore, faculty members might utilize more active strategies to strengthen and assess students' learning. For example, engage the diverse learning styles within the class. Ask in-depth, open-ended questions, ask students to write brief reflections on the content learned that day or during previous classes, offer opportunities to apply their knowledge and solve problems presented in case studies, and promote the engagement of all students using online instruction. Studies have shown there is an increase in engagement and student responses when asked to respond to a discussion prompt electronically, as opposed to posing questions during class where only a select few students will respond.

\subsubsection{Elicit Feedback from Students to Improve Teaching}

Just as it is critical for faculty to engage in self-evaluation and reflection of their teaching effectiveness, it is also incumbent on faculty to engage in a continuous quest for student feedback designed to help faculty grow and become better instructors. Many instructors ignore this rich opportunity to engage in ongoing dialog with students to improve their teaching. One way to do this is to use a portion of the instructional block to review content and to review processes by which content was shared. For instance, at the end of a class session, instructors might pause and ask, "How did the process by which content was delivered help you, the student, learn the content?" Other questions to consider include, "What was muddy? What was clear? What could I, the instructor, do to clear up confusion or clarify points of misunderstanding?" This feedback can be provided in written or oral form and can be identifiable or anonymous. However the information gathered feedback helps instructors improve the delivery of content and reflect on their teaching practices.

In addition to eliciting feedback, it is equally important for instructors to revisit adjustments and changes that have been made and to seek additional feedback from students. By doing so, the instructor is engaging in a continuous cycle of improvement that honors students' voices and respects students as partners in the learning process. help in these processes. This is empowering and helps reluctant students become active learning community participants. Tools that promote an active learning community include Learning Expressways folders (Smith et al., 2018), exit slips, and use of the Cue Do Review process (Kohler-Evans \& Rutledge, 2019).

\section{Conclusion}

In closing, providing college students with experiences that prepare them for the workforce and the rest of their lives is a daunting task. Knowing that education is such an essential element to a successful life makes the responsibility all the more critical. The issues surrounding the provision of a life-changing experience through the acquisition of a college education are complex. Nevertheless, faculty must carefully examine their responsibilities for educating tomorrow's teachers, lawyers, engineers, medical professionals, and leaders. We must seek ways to challenge our students to express their doubts, fears, beliefs, views, and dreams.

Further, we must choose those delivery methods that meet the needs of every student through authentic and relevant experiences that utilize multiple means of involvement, including using technology to connect with students. We must evaluate ourselves through a careful examination of our practices, strategies, and methodologies. In addition, we serve students best when we use multiple measures of assessment of their work. Lastly, we must never cease to examine our content, looking for ways to ensure that what we teach meets the highest standards. Although the responsibilities of faculty in today's college classroom seem overwhelming at times, it behooves us to remember that instructing the next generation is not just a responsibility but a privilege. 


\section{REFERENCES}

[1] Bledsoe, T. S. \& Baskin, J. J. (2014). Recognizing student fear: The elephant in the classroom. College Teaching, 62, 32-41. https://doi.org/10.1080/87567555.2013.831022

[2] Bok, D. (2013). Higher Education in America. Princeton University Press.

[3] Brannon, T.A. (2005). Learning interactivity in higher education: Comparing face-to-face, hybrid, and online instruction. Distance Learning, 2(2), 1-8.

[4] Brouse, C. H., Basch, C. E., LeBlanc, M., McKnight, K. R. \& Lei, T. (2010). College students' academic motivation: Differences by gender, class, and source of payment. College Quarterly, 13, 110. http://www.collegequarterly.ca/2010-vol13-num01-winter/brouse-basch-leblanc-mcknightlei.html

[5] Brown, M. M., \& Starrett, T. (2017, April 7). Fostering student connectedness: Building relationships in the classroom. Faculty Focus. https://www.facultyfocus.com/articles/teaching-andlearning/fostering-student-connectedness-building-relationships-classroom/

[6] Costa, A. (Ed.). (2001). Developing Minds: A Resource book for Teaching Thinking. ASCD.

[7] Dewey, J. (1915). The school and society. The University of Chicago Press.

[8] Dosch, M. \& Zidon, M. (2014). "The course fit us": Differentiated instruction in the college classroom. International Journal of Teaching and Learning in Higher Education, 26 (3), 343-357.

[9] Frisby, B. N. \& Myers, S. A. (2008). The relationships among perceived instructor rapport, student participation, and student learning outcomes. Texas Speech Communication Journal, 33, 27-34.

[10] Great Schools Partnership. (2014). Competency-based Learning. The Glossary of Education Reform: For journalists, parents, and community members. https://www.edglossary.org/competency-basedlearning/

[11] Great Schools Partnership. (2015). Personalized Learning. The Glossary of Education Reform: For journalists, parents, and community members. https://www.edglossary.org/personalized-learning/

[12] Hearn, J. C. (2006). Student Success: What Research Suggests for Policy and Practice. https://nces.ed.gov/npec/pdf/synth_Hearn.pdf

[13] Jorgenson, D. A., Farrell, L., Fudge, J. L. \& Pritchard, A. (2018). College connectedness: The student perspective. Journal of the Scholarship of Teaching and Learning,18 (1), 75-95. https://doi.org/10.14434/josotl.v18i1.22371

[14] Kohler-Evans, P. \& Rutledge, C. (2019, April 8). Recipe for teaching: Cue-Do-Review. Faculty Focus. https://www.facultyfocus.com/articles/effective-teaching-strategies/recipe-for-teaching-cuedo-review/

[15] Kohler-Evans, P., Rutledge, C.D. \& Barnes, C.D. (2019). Universal design for learning in the university classroom. International Research in Higher Education, 4 (1), 3844.https://doi.org/10.5430/irhe/v4n1p38

[16] Lenz, B. K., Schumaker, J. B., Deshler, \& Bulgren, J. A (1998). The course organizer routine.Edge Enterprises.

[17] Martinez, M. (2020). 6 Powerful Strategies for Deeper Learning in Your Classroom. Teachingthought.com https://www.teachthought.com/learning/6-powerful-strategies-deeper-learningclassroom/

[18] Marzilli, C., Delello, J., Marmion, S., McWhorter, R., Roberts, P. \& Marzilli, T. S. (2014). Faculty attitudes towards integrating technology and innovation. International Journal of Integrating Technology in Education, 3, 1-20. https://doi.org/10.5121/ijite.2014.3101

[19] Mintz, S. (2016). Differentiated instruction in the college classroom. Inside Higher Education. https://www.insidehighered.com/blogs/higher-ed-gamma/differentiated-instruction-college-classroom

[20] Miron, M. (1988). Students' evaluation and instructors' self-evaluation of university instruction. Higher Education, 17, 175-181. https://www-jstor-org.ucark.idm.oclc.org/stable/3446765

[21] Nbss.ie. (n.d.) Solution Focused Thinking | NBSS. <https://www.nbss.ie/nbss-model-ofsupport/level-1-school-wide-support-for-all-students/solution-focused-thinking>

[22] Roettger, C., Roettger, L. O. \& Walugembe, F. (2007). Teaching: More than just lecturing. Journal of University Teaching \& Learning Practice, 4(2), 119-133.

[23] Smith, H. H., Sanchez, A., Peterson-Ahmad, M., Woodbury, C, \& Mitchell, B.B. (2018) using Learning Express-Ways in special education teacher preparation: Developing student-faculty relationships as a path to partnership. The Journal of Special Education Apprenticeship, 3(7). https://files.eric.ed.gov/fulltext/EJ1201611.pdf 
International Journal of Education (IJE) Vol.8, No.4, December 2020

[24] Smith, B. L. \& MacGregor, J. (1992). What is Collaborative Learning?. In A. Goodsell, M. Maher, V. Tinto, B. L. Smith, \& MacGregor, J. Collaborative Learning: A Sourcebook for Higher Education. (pp. 9-22). National Center on Postsecondary Teaching, Learning, and Assessment (NCTLA).

[25] Tomlinson, C.A. (2001). How to differentiate instruction in mixed ability classrooms (2nd ed.). Association for Supervision and Curriculum Development.

\section{AUTHORS}

Dr. Candice Barnes serves as the Distinguished Education Equity Fellow and an associate professor for the College of Education at the University of Central Arkansas. She is also an Executive Coach and coowner of Parker Education \& Development, LLC, and owner of Couture Crafting. Dr. Barnes presents nationally and internationally on cultural conflict recovery, the intersection of cultural humility and civility as a de-biasing strategy, examining personality structures for high-engagement, and the development of cross-cultural alliances.

Dr. Patty Kohler-Evans is professor in the College of Education at the University of Central Arkansas. She serves as an Executive Coach for school principals and has co-authored five books on inclusive practice, mentoring new teachers, and collaborative practice. Dr. Kohler-Evans co-directs the UCA Mashburn Center for Learning which provides evidence-based practices to public school educators throughout the state.

Mrs. Rachel Wingfield is a $\mathrm{PhD}$ candidate completing a pre-doctoral internship to be a licensed psychologist. Research interests include teacher preparation, behavior training in the school setting, and caregiver self-efficacy. 